\section{References}

1 Bartter FC, Schwartz WB. The syndrome of inappropriate secretion of antidiuretic hormone. Am f Med 1967;42:790-806.

${ }^{2}$ Forrest JN Jr, Cox M, Hong C, Morrison G, Bia M, Singer I. Superiority of demeclocycline over lithium in the treatment of chronic syndrome of inappropriate secretion of antidiuretic hormone. N Engl f Med 1978; 298:173-7.

${ }^{3}$ De Troyer A. Demeclocycline: treatment for syndrome of inappropriate antidiuretic hormone secretion. $7 A M A$ 1977;237:2723-6.

' Decaux G, Brimioulle S, Genette F, Mockel J. Treatment of the syndrome of inappropriate secretion of antidiuretic hormone by urea. $\mathrm{Am} \mathcal{F ~ M e d}$ $1980 ; 69: 99-106$
${ }^{5}$ Decaux G, Unger J, Mockel J. Urea therapy for inappropriate antidiuretic hormone secretion from tuberculous meningitis. $\mathcal{F A M} A 1980$; 244:589-90.

${ }^{6}$ Decaux G, Genette F, Mockel J. Hypouremia in the syndrome of inappropriate secretion of antidiuretic hormone. Ann Intern Med 1980; $93: 716-7$.

${ }^{7}$ Decaux G, Waterlot Y, Genette F, Mockel J. Treatment of the syndrome of inappropriate secretion of antidiuretic hormone with furosemide. $N$ Engl F Med $1981 ; 304: 329-30$.

${ }^{8}$ Javid $M$, Setlage $\mathrm{P}$. Effect of urea on cerebrospinal fluid pressure in human subjects. $\mathcal{F} A M A$ 1956;160:943-9.

(Accepted 5 August 1981)

\title{
Acute appendicitis in nine British towns
}

\author{
D J P BARKER, A LIGGINS
}

\begin{abstract}
The incidence of acute appendicitis was compared among residents in nine towns in England and Wales, the towns having been chosen so that three were in the north, three in the central latitude band, and three in the south. Each group of three towns comprised one with "better," one with "intermediate," and one with "worse" socioeconomic conditions. The data were derived from hospital records for the years 1974-7. Hospital discharge rates for acute appendicitis were higher in the three northern towns in both sexes and all age groups. There was no consistent variation with the socioeconomic state of the towns.

The distribution of appendicitis in the nine towns differed from that of other "diseases of Western civilisation" and so weighs against the hypothesis of similar dietary influences in the aetiology of acute appendicitis and these other diseases. These findings are being followed up by dietary surveys in the towns.
\end{abstract}

\section{Introduction}

Donnan and Lambert ${ }^{1}$ analysed rates of discharge from hospital for acute appendicitis by hospital region, using data from the one in 10 sample of discharges that constitutes the Hospital Inpatient Enquiry. They found that regional discharge rates showed some consistent differences over time-for example, East Anglia had consistently low rates. Regions, however, are large and heterogeneous geographical units, and the value of regional comparisons is therefore limited. This paper compares the incidence of appendicitis in nine county boroughs, selected to encompass the range of socioeconomic conditions and spread of latitude in England and Wales.

\section{Methods}

The method of selection of the nine towns has been described elsewhere. ${ }^{2}$ In summary, the 83 largest county boroughs in England

MRC Environmental Epidemiology Unit, University of Southampton, Southampton

D J P BARKER, FRCP, PHD, professor of clinical epidemiology

A LIGGINS, BM, research assistant and Wales were classified into three equal groups having "better," "intermediate," and "worse" social and economic conditions. This classification was effected using a range of intercorrelated social and economic variables. The county boroughs were also divided into three groups according to latitude. One town was selected from each of the nine socioeconomic-latitude groupings. In the north the towns were York, Wakefield, and Preston; in the central latitude band Chester, Derby, and Stoke; and in the south Ipswich, Plymouth, and Newport.

Hospital Activity Analysis (HAA) data were obtained for each county borough from the regional health authorities. These data comprised tabulations of the numbers of patients resident in the county boroughs who had (1) been discharged from a hospital within the region during the period from 1 January 1974 to 31 December 1977 , (2) been diagnosed as having acute appendicitis (ICD numbers 540,541 , eighth revision), (3) been admitted as emergencies, and (4) undergone appendicectomy (OPCS numbers 441, 444). Use of these criteria was intended to exclude patients with non-acute appendicitis.

These data, however, will necessarily be inaccurate. Several conditions mimic acute appendicitis, and a proportion of removed appendices are histologically normal. ${ }^{3}$ Yet for various reasons in some of these cases the diagnosis of appendicitis still appears on the HAA records. For example, a surgeon may describe the appendix as appearing "slightly inflamed" and send the specimen for histological examination. If HAA coding is done before the histological report is received the patient is likely to be recorded as having acute appendicitis irrespective of subsequent histological findings.

Therefore, variations between the towns in the incidence of acute appendicitis, as calculated from HAA data, might reflect different HAA coding practices or surgical policies rather than true variations in incidence. For this reason it was necessary to correct the data by determining the proportion of removed appendices that were actually inflamed. Each town was visited and the pathology reports on appendicectomy specimens received during one year were inspected. In eight towns the year chosen was 1976; in the other town the records for 1977 were more complete than those for 1976 and were used instead. The appendices were classified into two groups according to the histology reports-namely, "inflamed," if polymorphonuclear leucocytes had been seen in the muscular layer of the appendicular wall, and "normal." The few equivocal reports were assessed by a consultant pathologist in Southampton.

In all towns except Preston the histology results were matched with the HAA listings of patients discharged during the same year. The proportion of patients coded as having acute appendicitis, according to the criteria described above, whose appendices were histologically normal was thereby obtained for each town. This figure was used to correct the HAA rates for the entire four-year period.

In Preston only $10 \%$ of removed appendices were sent for histological examination. Since these were unlikely to be representative of all removed appendices it was not possible to correct the HAA rates using histological data. An alternative method, based on the surgeons' comments, was used and is described below. 


\section{Results}

Table I shows average annual discharge rates for acute appendicitis and total numbers of cases over the four years 1974-7. The rates were based on a total of 5785 patients and were standardised for age and sex to allow for the differing population structures of the towns. (The direct method of standardisation was used, the combined populations of the nine towns being the standard.) Rates varied from 16.3/10 000 in Preston to 8.5 in Stoke. Within each socioeconomic group the northern town had the highest rate. There was no consistent relation with socioeconomic conditions.

TABLE I-Average annual hospital discharge rates for acute appendicitis standardised for age and sex per 10000 population, 1974-7 (5785 patients)

\begin{tabular}{|c|c|c|c|c|c|}
\hline \multirow{2}{*}{ Latitude } & & \multicolumn{3}{|c|}{ Social and economic conditions } & \multirow{2}{*}{ All conditions } \\
\hline & & Better & Intermediate & Worse & \\
\hline $\begin{array}{l}\text { North: } \\
\text { Rate .. } \\
\text { No of cases }\end{array}$ & $\because$ & $\begin{array}{c}13.5 \\
560 \\
\text { (York) }\end{array}$ & $\begin{array}{c}13.9 \\
323 \\
\text { (Wakefield) }\end{array}$ & $\begin{array}{c}16.3 \\
639 \\
\text { (Preston) }\end{array}$ & $14 \cdot 6$ \\
\hline $\begin{array}{l}\text { Central: } \\
\text { Rate } \\
\text { No of cases }\end{array}$ & $\begin{array}{l}\cdots \\
\cdots\end{array}$ & $\begin{array}{c}10 \cdot 6 \\
268 \\
\text { (Chester) }\end{array}$ & $\begin{array}{c}12 \cdot 2 \\
1076 \\
\text { (Derby) }\end{array}$ & $\begin{array}{c}8.5 \\
905 \\
\text { (Stoke) }\end{array}$ & $10 \cdot 4$ \\
\hline $\begin{array}{l}\text { South: } \\
\text { Rate . . } \\
\text { No of cases }\end{array}$ & $\because$ & $\begin{array}{c}8.9 \\
444 \\
\text { (Ipswich) }\end{array}$ & $\begin{array}{c}10 \cdot 5 \\
1013 \\
\text { (Plymouth) }\end{array}$ & $\begin{array}{c}12.3 \\
557 \\
\text { (Newport) }\end{array}$ & $10 \cdot 6$ \\
\hline All latitudes & $\cdots$ & $11 \cdot 0$ & $12 \cdot 2$ & $12 \cdot 4$ & \\
\hline
\end{tabular}

In towns other than Preston there were a total of 1399 patients during the year (1976 or 1977) selected for study of histology reports. Reports were found for all except $174(12 \%$; range for individual towns $7-18 \%$ ). Among the 1225 patients for whom reports were found the percentage classified in the HAA listing as having acute appendicitis and in whom the diagnosis was confirmed histologically varied between towns from $70 \%$ to $93 \%$. Table II shows that these percentages differed not only between towns but also, as would be expected, with age and sex, being higher in male than female patients and higher in older patients. For each town, except Preston, the HAA-listed patients for the four years were subdivided according to the age-sex groups shown in table II. The numbers in each group were multiplied by the proportion of histologically proved cases recorded in that group during the year when histology reports were studied. The result was used to derive "corrected" average annual rates standardised for age and sex (table III).

TABLE II-Percentages of patients in whom diagnosis of acute appendicitis was confirmed histologically (1225 patients, Preston being excluded)

\begin{tabular}{lccccc}
\hline & \multicolumn{5}{c}{ Age (years) } \\
\cline { 2 - 6 } & & $0-14$ & $15-29$ & $30+$ & All ages \\
\hline Male & $\ldots$ & 85 & 83 & 88 & 85 \\
Female & $\ldots$ & 68 & 64 & 77 & 70 \\
\hline Both sexes &.. & 76 & 73 & 82 & 77
\end{tabular}

TABLE III-Corrected* average annual hospital discharge rates for acute appendicitis standardised for age and sex per 10000 population, 1974-7

\begin{tabular}{|c|c|c|c|c|c|}
\hline \multirow{2}{*}{ Latitude } & & \multicolumn{3}{|c|}{ Social and economic conditions } & \multirow{2}{*}{ All conditions } \\
\hline & & Better & Intermediate & Worse & \\
\hline$\overline{\text { North }}$ & $\cdots$ & $\begin{array}{c}10.9 \\
\text { (York) }\end{array}$ & $\begin{array}{c}11 \cdot 0 \\
\text { (Wakefield) }\end{array}$ & $\begin{array}{c}12 \cdot 7 \\
\text { (Preston) }\end{array}$ & 11.5 \\
\hline Central .. & . & $\begin{array}{c}7.5 \\
\text { (Chester) }\end{array}$ & $\begin{array}{c}8 \cdot 7 \\
\text { (Derby) }\end{array}$ & $\begin{array}{c}\mathbf{6} \cdot \mathbf{8} \\
\text { (Stoke) }\end{array}$ & $7 \cdot 7$ \\
\hline South & . & $\begin{array}{c}8 \cdot 4 \\
\text { (Ipswich) }\end{array}$ & $\begin{array}{c}7 \cdot 3 \\
\text { (Plymouth) }\end{array}$ & $\begin{array}{c}8.9 \\
\text { (Newport) }\end{array}$ & $8 \cdot 2$ \\
\hline All latitudes & $\ldots$ & 8.9 & $9 \cdot 0$ & $9 \cdot 5$ & \\
\hline
\end{tabular}

${ }^{*}$ For method of correction see text.
The corrected rate for Preston given in table III was derived from 3 the surgeons' comments on the appearance of the appendix at $\stackrel{\mathbb{Q}}{\mathscr{Q}}$ operation. During 1976, 164 patients were listed in HAA data as $C$ having acute appendicitis. In 142 of these cases the surgeon described $\widehat{\supset}$ the removed appendix as inflamed. By using records in two other towns in the survey we compared surgeons' descriptions with histological reports. In the first town 86 out of 95 removed appendices $\mathbb{\infty}$ were described by the surgeon as inflamed. In seven of these 86 inflammation was not confirmed histologically. The rate of false- $\varrho$ positive diagnoses was therefore $7 / 86(8 \cdot 1 \%)$. In the second town 121 out of 138 removed appendices were described as inflamed but in $10 \stackrel{\overrightarrow{\mathrm{S}}}{\mathrm{F}}$ inflammation was not confirmed histologically. The rate of false- $\vec{\theta}$ positive diagnoses was therefore $10 / 121(8 \cdot 3 \%)$. In neither town were there any false-negative diagnoses- that is, appendices described by the surgeon as not inflamed but reported by the pathologists to be

TABLE IV-Corrected average annual discharge rates for acute appendicitis $\vec{\circ}$ standardised for age per 10000 males, 1974-7

\begin{tabular}{|c|c|c|c|c|c|}
\hline \multirow{2}{*}{ Latitude } & & \multicolumn{3}{|c|}{ Social and economic conditions } & \multirow{2}{*}{ All conditions } \\
\hline & & Better & Intermediate & W'orse & \\
\hline North & . & $\begin{array}{c}12 \cdot 7 \\
\text { (York) }\end{array}$ & $\begin{array}{c}14.5 \\
\text { (Wakefield) }\end{array}$ & $\begin{array}{c}13 \cdot 4 \\
\text { (Preston) }\end{array}$ & 13.5 \\
\hline Central .. & $\cdots$ & $\begin{array}{c}8.9 \\
\text { (Chester) }\end{array}$ & $\begin{array}{c}10 \cdot 3 \\
\text { (Derby) }\end{array}$ & $\begin{array}{c}8 \cdot 2 \\
\text { (Stoke) }\end{array}$ & $9 \cdot 1$ \\
\hline South & . & $\begin{array}{c}10 \cdot 1 \\
\text { (Ipswich) }\end{array}$ & $\begin{array}{c}8 \cdot 8 \\
\text { (Plymouth) }\end{array}$ & $\begin{array}{c}11 \cdot 6 \\
\text { (Newport) }\end{array}$ & $10 \cdot 2$ \\
\hline All latitudes & . & $10 \cdot 6$ & $11 \cdot 2$ & $11 \cdot 1$ & \\
\hline
\end{tabular}

TABLE $\mathrm{v}-$ Corrected average annual discharge rates for acute appendicitis standardised for age per 10000 females, 1974-7

\begin{tabular}{|c|c|c|c|c|c|}
\hline \multirow{2}{*}{ Latitude } & & \multicolumn{3}{|c|}{ Social and economic conditions } & \multirow{2}{*}{ All conditions } \\
\hline & & Better & Intermediate & Worse & \\
\hline North & . & $9 \cdot 1$ & $\begin{array}{c}7 \cdot 7 \\
0\end{array}$ & $12 \cdot 3$ & $9 \cdot 7$ \\
\hline Central .. & $\cdots$ & $\begin{array}{c}6 \cdot 1 \\
\text { (Chester) }\end{array}$ & $\begin{array}{c}\text { (w.1 } \\
\text { (Derby) }\end{array}$ & $\begin{array}{c}5 \cdot 4 \\
\text { (Stoke) }\end{array}$ & $6 \cdot 2$ \\
\hline South & .. & $\begin{array}{c}6 \cdot 7 \\
\text { (Ipswich) }\end{array}$ & $\begin{array}{c}5 \cdot 9 \\
\text { (Plymouth) }\end{array}$ & $\begin{array}{c}6 \cdot 4 \\
\text { (Newport) }\end{array}$ & $6 \cdot 3$ \\
\hline All latitudes & $\ldots$ & $7 \cdot 3$ & 6.9 & $8 \cdot 0$ & \\
\hline
\end{tabular}

TABLE VI-Corrected average annual discharge rates for acute appendicitis per 10000 population by age group 1974-7 (all towns, males and females combined)

\begin{tabular}{|c|c|c|c|}
\hline \multirow{2}{*}{ Latitude } & \multicolumn{3}{|c|}{ Age group (years) } \\
\hline & $0-14$ & $15-29$ & 30 and over \\
\hline $\begin{array}{l}\text { North .. } \\
\text { Central } \\
\text { South .. }\end{array}$ & $\begin{array}{l}18 \cdot 4 \\
11 \cdot 4 \\
13 \cdot 4\end{array}$ & $\begin{array}{l}21.3 \\
12.9 \\
13.9\end{array}$ & $\begin{array}{l}4 \cdot 8 \\
3 \cdot 9 \\
3 \cdot 7\end{array}$ \\
\hline
\end{tabular}

inflamed. An average of the rates of false-positive diagnoses in the two towns for each age-sex group, combined with a zero rate of falsenegative diagnoses, was applied to the 1976 data to obtain age- and sex-specific proportions of proved cases. These proportions were then applied to the entire data for Preston to give the rate of $12 \cdot 7 / 10000$ shown in table III.

The corrected rates showed a similar pattern to the uncorrected ones. There was a twofold variation from 12.7 in Preston to 6.8 in Stoke. Within each socioeconomic group the northern town had the highest rate, and the combined rate for the three northern towns was 11.5/10 000 compared with $7 \cdot 7$ for the central towns and 8.2 for $\overline{0}$ the south. There was no consistent relation between socioeconomic $\overrightarrow{\mathbb{D}}$ conditions and discharge rates within each latitude band. Tables IV $\stackrel{9}{\Phi}$ and $\mathrm{V}$ show that the higher rates in the northern town within each $\unrhd$ socioeconomic group occurred among both males and females. (In each town the rate among males was higher than the rate among 8 females.) Likewise, in the three age groups 0-14, 15-29, and $\frac{0}{0}$ $30+$ years the rates were always higher in the northern town in each socioeconomic group. Table VI summarises the age distribution, giving age-specific rates by latitude for all towns combined. 


\section{Discussion}

This study has shown variation in hospital discharge rates for acute appendicitis among nine towns in England and Wales. Although the data used comprised HAA listings of acute admissions of patients undergoing appendicectomy, there were, as predicted at the outset, a proportion of patients in whom the actual diagnosis was not appendicitis. The principal reason for these errors is that HAA coding may be carried out before a histological report has been received. The data were therefore corrected to allow for this. We have no data on the frequency with which patients with appendicitis were miscoded as having some other disorder and were therefore not included in the survey. Clinical diagnosis of acute appendicitis almost always results in an appendicectomy; and, since the occurrence and nature of an operation is almost invariably clearly stated in the notes, recording of operations in HAA systems is more accurate than that of diagnoses. Therefore, it seems unlikely that our results were much influenced by underascertainment.

Since the histological data were not all independently reviewed by one pathologist some of th: variation between towns may possibly have resulted from systematic differences in pathologists' opinions of early lesions. In most inflamed appendices, however, the pathological appearance is unequivocal, and a variation in rates of the magnitude observed is unlikely to be explicable by varying pathological criteria.

Since diagnosis of acute appendicitis by a general practitioner will lead to admission to hospital the corrected hospital discharge rates (table III) are likely to approximate to the actual incidences of the disease in the nine towns. The rates in the three northern towns were higher than those in the central and southern ones. This was seen in both sexes (tables IV and V) and in all age groups (table VI). Within each latitude band there was no consistent variation with the socioeconomic state of the towns. Table VI shows that in the youngest age group the difference between the rates in the northern towns and the other towns was similar to that in the two older age groups. This implies that the northern excess is due to influences still present in the environment. Furthermore, it suggests that the decline in the incidence of appendicitis in England and Wales that has occurred over the past 20 years $^{1}$ is not being accompanied by any pronounced decrease in the north-south difference.

In having an association with latitude but not socioeconomic state in the nine towns appendicitis differs from mortality from all causes. Mortality increases sharply with both increasing latitude and worsening socioeconomic conditions. ${ }^{2}$ The distribution of appendicitis in the nine towns also differs from that of other so-called "diseases of Western civilisation." Non-insulin-dependent diabetes shows little variation with latitude but a greatly increased incidence in towns with worse socioeconomic conditions. ${ }^{5}$ In contrast, the prevalence of gall stones at necropsy, and mortality from ischaemic heart disease, are associated with both latitude and socioeconomic conditions but there is an inverse correlation between the distributions of the two diseases. ${ }^{2}$ These findings weigh against the hypothesis of similar dominant dietary influences in the aetiology of appendicitis and other diseases of Western civilisation. ${ }^{4}$

Sixty years ago Rendle Short, ${ }^{\circ}$ aware of the upsurge in appendicitis that had occurred around the turn of the century, compared the epidemiological data on the disease and the changes that had occurred in the British diet since 1880 . He concluded that the appearance of many cases of appendicitis was due to "the relatively less quantity of cellulose eaten on account of the wider use of imported foods." Burkitt ${ }^{7}$ endorsed this conclusion but suggested increased sugar consumption as a cofactor.

The National Food Survey has shown that diet in England and Wales varies with latitude. ${ }^{8}$ For example, the three northern regions (northern, north-west, and Yorkshire and Humberside) have the lowest consumption of green vegetables. The range of variation is large, being from $300 \mathrm{~g}$ per person per week in the northern region to $533 \mathrm{~g}$ in the south-west. The survey, however, uses a regional sampling frame, and regions are too heterogeneous to permit use of the survey data to describe the diet in a particular town. Special surveys are necessary to correlate the geographical variations in the incidence of appendicitis in the nine towns with variations in diet, and these have been initiated. We hope that the outcome will be new evidence on dietary influences in the aetiology of acute appendicitis.

We wish to record our gratitude to the late Mrs Judith Parry, who assisted with this survey. We are also grateful to the pathologists in the nine towns, who permitted us to use their records, and to the staff at the regional health authorities who provided HAA data.

\section{References}

Donnan SPB, Lambert PM. Appendicitis: incidence and mortality. Population Trends 1976;5:26-8.

2 Barker DJP, Gardner MJ, Power C, Hutt MSR. Prevalence of gall stones at necropsy in nine British towns: a collaborative study. $\mathrm{Br} \mathrm{Med} \mathcal{F}$ $1979 ;$ ii:1389-92.

${ }^{3}$ Gilmore OJA. Appendicitis and mimicking conditions. Lancet 1975;ii: 421-4.

4 Burkitt DP. Some diseases characteristic of modern Western civilisation. Br Med F 1973;i:274-7.

5 Power C, Barker DJP, Gardner MJ. Incidence of diabetes in nine towns. 7 Epidemiol Community Health $1981 ; 35: 152$.

6 Short AR. The causation of appendicitis. Br 7 Surg 1920;8:171-88.

${ }^{7}$ Burkitt DP. The aetiology of appendicitis. Br F Surg 1971 ;58:695-9.

${ }^{8}$ National Food Survey Committee. Household food consumption and expenditure: 1978. London: HMSO, 1980.

(Accepted 27 fuly 1981)
CALAMINT, OR MOUNTAIN-MINT is a small herb, seldom rising above a foot high, with square hairy, and woody stalks, and two small hoary leaves set at a joint, about the height of Marjoram, or not much bigger, a little dented about the edges, and of a very fierce or quick scent, as the whole herb is: The flowers stand at several spaces of the stalk, from the middle almost upwards, which are small and gaping like to those of the Mints, of a pale bluish colour: After which follow small, round blackish seed. The root is small and woody, with divers small strings spreading within the ground, and dies not, but abides many years.

It grows on heaths, and uplands, and dry grounds, in many places of this land. They flower in July and their seed is ripe quickly after.

It is an herb of Mercury, and a strong one too, therefore excellent good in all afflictions of the brain. The decoction of the herb being drank, brings down women's courses, and provokes urine. It is profitable for those that are bursten, or troubled with convulsions or cramps, with shortness of breath, or choleric torments and pains in their bellies or stomach; it also helps the yellow-jaundice, and stays vomiting, being taken in wine. Taken with salt and honey, it kills all manner of worms in the body. It helps such as have the leprosy, either taken inwardly, drinking whey after it, or the green herb outwardly applied. It hinders conception in women, but either burned or strewed in the chamber, it drives away venomous serpents. It takes away black and blue marks in the face, and makes black scars become well coloured, if the green herb (not the dry) be boiled in wine, and laid to the place, or the place washed therewith. Being applied to the huckle-bone, by continuance of time, it spends the humours, which cause the pain of the sciatica. The juice being dropped into the ears, kills the worms in them. The leaves boiled in wine, and drank, provoke sweat, and open obstructions of the liver and spleen. It helps them that have a tertian ague (the body being first purged) by taking away the cold fits. The decoction hereof, with some sugar put thereto afterwards, is very profitable for those that be troubled with the over-flowing of the gall, and that have an old cough, and that are scarce able to breathe by shortness of their wind; that have any cold distemper in their bowels, and are troubled with the hardness or the spleen, for all which purposes, both the powder, called Diacaluminthes, and the compound Syrup of Calamint are the most effectual. Let no women be too busy with it, for it works very violent upon the feminine part. (Nicholas Culpeper (1616-54) The Complete Herbal, 1850.) 